\title{
Effects of radioactive ${ }^{125} \mathrm{I}$ on apoptosis of HGC-27 gastric cancer cells
}

\author{
YONG YANG $^{1}$, AIFEI CHEN ${ }^{1}$, JUN MA $^{1}$, AIPING WU ${ }^{1}$ and FAZHEN XU ${ }^{2}$ \\ ${ }^{1}$ Department of Oncology, Huai'an TCM Hospital Affiliated to Nanjing University of Chinese Medicine, \\ Huai'an, Jiangsu 223001; ${ }^{2}$ Department of Gastroenterology, Lianshui County People's Hospital, \\ Huai'an, Jiangsu 223400, P.R. China
}

Received November 28, 2018; Accepted July 07, 2019

DOI: $10.3892 / 01.2019 .10832$

\begin{abstract}
Effects of radioactive ${ }^{125} \mathrm{I}$ particles at different doses on apoptosis of HGC-27 gastric cancer cells were investigated. HGC-27 gastric cancer cell suspension was used to establish a tumor-bearing mouse model. The model was reared for approximately 3 weeks and then divided into the control group (implanted with blank particles), the low dose group (implanted with $1.48 \times 10^{-7} \mathrm{~Bq}{ }^{125} \mathrm{I}$ particles), the medium dose group (implanted with $2.22 \times 10^{-7} \mathrm{~Bq}{ }^{125} \mathrm{I}$ particles) and the high dose group (implanted with $2.96 \times 10^{-7} \mathrm{~Bq}{ }^{125}$ I particles) ( $\mathrm{n}=15$ per group). Six nude mice were randomly sacrificed to collect the tumor tissue and measure tumor volume and mass. TUNEL (TdT-mediated dUTP nick-end labeling) was used for detecting apoptosis of tumor cells, and reverse transcription-quantitative polymerase chain reaction (RT-qPCR) for detecting the relative expression of Bax, caspase-3 and caspase-8. On the 28th day after implantation, the apoptotic rate in the low, medium and high dose groups was significantly higher than that in the control group, which in the medium and high dose groups was significantly lower than that in the low dose group $(\mathrm{P}<0.05)$. On the 28th day after implantation, the relative expression of Bax, caspase-3 and caspase- 8 mRNA in the control group was significantly lower than that in the low, medium and high dose groups $(\mathrm{P}<0.05)$, which in the low dose group was significantly higher than that in the medium and high dose groups $(\mathrm{P}<0.05) .{ }^{125}$ I particles can inhibit the growth of HGC-27 gastric cancer cell transplants and promote the expression of Bax, caspase- 3 and caspase- 8 mRNA in the tumor tissue. Low-dose ${ }^{125} \mathrm{I}$ particles are significantly more effective than medium- or high-dose ${ }^{125} \mathrm{I}$ particles.
\end{abstract}

Correspondence to: Dr Fazhen Xu, Department of Gastroenterology, Lianshui County People's Hospital, 6 Hongri Road, Huai'an, Jiangsu 223400, P.R. China

E-mail: x8r23m@163.com; xfz10@163.com

Key words: interstitial irradiation, ${ }^{125} \mathrm{I}$, gastric cancer, apoptosis, dose, tumor-bearing mice

\section{Introduction}

Malignant tumors are recognized worldwide as public health and safety issues. Global cancer statistics in 2012 showed that gastric cancer was clinically common, and cancer statistics in China showed that there were 679,100 new patients and 498,000 deaths in 2015 . The high incidence and mortality rates of the disease need to be urgently reduced (1-3). Operation, the best way to clinically treat cancer, improves conditions through excising the focal zone. However, early gastric cancer shows no obvious abnormalities, and patients are admitted to hospital after they feel unwell. As a result, most patients miss the best treatment time and can only be conservatively treated to alleviate conditions $(4,5)$.

Therapeutic regimens for cancer have been increasing with the improvement of medical levels and technology. External radiotherapy combined with chemotherapy which has been widely used in the treatment of the middle and advanced stages of cancer effectively prolongs the survival time of patients. However, toxic and side effects easily occur during the treatment, and the patients may even suffer from organ failure (6,7). According to a recent study, as a new and effective adjuvant treatment for tumors and a new option especially for patients with poor efficacy of traditional chemotherapy regimens, interstitial irradiation causes a small trauma to the body and has an appropriate radiation radius to accurately treat the local area of lesions (8). ${ }^{125} \mathrm{I}$ is the main particle of internal radiotherapy and effective in the treatment of lung, prostate, pancreatic, rectal and gastric cancer (9-11). However, its specific mechanism on inhibiting tumor growth remains unclear. Apoptosis, which is an important means of the clinical treatment of tumors, refers to the autonomous and orderly death of cells controlled by genes in order to maintain homeostasis (12).

Therefore, the mechanism of ${ }^{125} \mathrm{I}$ on anti-apoptosis of gastric cancer HGC-27 cells was explored in this study to provide a reference for clinical treatment.

\section{Materials and methods}

Animal sources. Sixty male SPF (specific pathogen free) nude mice BALB/c (Beijing Vital River Laboratory Animal Technology Co., Ltd., weighing $20 \pm 2 \mathrm{~g}$ and aged 4 weeks, 
Table I. Primer sequences.

\begin{tabular}{lll}
\hline Genes & \multicolumn{1}{c}{ Upstream primers } & Downstream primers \\
\hline Bax & 5'-GGGTTGTCGCCCTTTTCTAC-3' & 5'-GGTGAGGAGGCTTGAGGAGT-3' \\
Caspase-3 & 5'-AAGGCAGAGCCATGGACCAC-3' & 5'-CTGGCAGCATCATCCACACATAC-3' \\
Caspase-8 & 5'-GTTCTCTCAGTTGCCTTTC-3' & 5'-AGCTGTAACCTGTCGCCGAGTCCC-3' \\
GAPDH & 5'-GCACCGTCAAGGCTGAGAAC-3' & 5'-TGGTGAAGACGCCAGTGGA-3'
\end{tabular}

Table II. Comparison of tumor volume $\left(\mathrm{mm}^{3}\right)$.

\begin{tabular}{|c|c|c|c|c|c|}
\hline Groups & $\begin{array}{c}\text { Before } \\
\text { implantation } \\
\text { (Day 0) }\end{array}$ & $\begin{array}{c}\text { 7th day } \\
\text { after } \\
\text { implantation }\end{array}$ & $\begin{array}{c}\text { 14th day } \\
\text { after } \\
\text { implantation }\end{array}$ & $\begin{array}{c}\text { 21st day } \\
\text { after } \\
\text { implantation }\end{array}$ & $\begin{array}{c}\text { 28th day } \\
\text { after } \\
\text { implantation }\end{array}$ \\
\hline Control group $(n=6)$ & $548.7 \pm 24.5$ & $580.1 \pm 24.5$ & $605.4 \pm 16.2^{\mathrm{a}}$ & $609.5 \pm 22.7^{\mathrm{a}}$ & $608.8 \pm 24.5^{\mathrm{a}}$ \\
\hline Low dose group $\left(\mathrm{n}=6,1.48 \times 10^{-7} \mathrm{~Bq}^{125} \mathrm{I}\right)$ & $551.4 \pm 24.1$ & $475.4 \pm 20.1^{\mathrm{a}, \mathrm{e}}$ & $357.1 \pm 16.7^{\mathrm{a}, \mathrm{b}, \mathrm{e}}$ & $325.6 \pm 15.1^{\mathrm{a}, \mathrm{b}, \mathrm{e}}$ & $230.1 \pm 14.2^{\mathrm{a}-\mathrm{e}}$ \\
\hline Medium dose group $\left(n=6,2.22 \times 10^{-7} \mathrm{~Bq}^{125} \mathrm{I}\right)$ & $550.1 \pm 24.4$ & $461.2 \pm 17.3^{\mathrm{a}, \mathrm{e}}$ & $361.5 \pm 20.1^{\mathrm{a}, \mathrm{b}, \mathrm{e}}$ & $329.1 \pm 20.2^{\mathrm{a}-\mathrm{c}, \mathrm{e}}$ & $270.2 \pm 19.2^{\mathrm{a}-\mathrm{f}}$ \\
\hline High dose group $\left(\mathrm{n}=6,2.96 \times 10^{-7} \mathrm{~Bq}^{125} \mathrm{I}\right)$ & $557.1 \pm 21.6$ & $540.1 \pm 19.3^{\mathrm{e}-\mathrm{g}}$ & $330.1 \pm 22.2^{\mathrm{a}, \mathrm{b}, \mathrm{e}, \mathrm{g}}$ & $331.0 \pm 17.5^{\mathrm{a}, \mathrm{b}, \mathrm{e}}$ & $261.3 \pm 15.7^{\mathrm{a}-\mathrm{f}}$ \\
\hline
\end{tabular}

${ }^{\mathrm{a}} \mathrm{P}<0.05$ indicates a difference compared with before implantation, ${ }^{\mathrm{b}} \mathrm{P}<0.05$ indicates a difference compared with the 7 th day after implantation, ${ }^{\mathrm{c}} \mathrm{P}<0.05$ indicates a difference compared with the 14 th day after implantation. ${ }^{\mathrm{d}} \mathrm{P}<0.05$ indicates a difference compared with the 21 st day after implantation, ${ }^{\mathrm{e}} \mathrm{P}<0.05$ indicates a difference compared with the control group, ${ }^{\mathrm{f}} \mathrm{P}<0.05$ indicates a difference compared with the low dose group, ${ }^{\mathrm{g}} \mathrm{P}<0.05$ indicates that there is a difference compared with the medium dose group.

were reared by professionals for 1 week after being purchased. The indoor temperature was $21 \pm 2^{\circ} \mathrm{C}$, the indoor humidity was $50-70 \%$, with 12-h light/dark cycles and free access to food and water.

The study was approved by the Ethics Committee of Huai'an TCM Hospital Affiliated to Nanjing University of Chinese Medicine (Huai'an, China).

Main reagents and instruments. HGC-27 cells (Elabscience Biotechnology Inc., CL-0107), ${ }^{125}$ I particles (Tianjin Xiehe Medicine Technology Group Co., Ltd.), RPMI-1640 medium culture solution, $10 \%$ fetal bovine serum (FBS), penicillin-streptomycin (antibiotics) and TRIzol extraction reagent [Thermo Fisher Scientific (China) Co., Ltd., 61870044, 10099141, 15070063, 16096020], TransScript Two-Step RT-PCR SuperMix kit (TransGen Biotech, AT411-02). Primers for Bax, caspase-3, caspase-8 and GAPDH PCR (Table I) were designed and synthesized by Sangon Biotech (Shanghai) Co., Ltd. TUNEL apoptosis detection kit (Beyotime Biotechnology, C1091), PCR instrument (Applied Biosystems; Thermo Fisher Scientific, Inc., 7500).

Cell culture. HCG-27 cells were resuscitated, transferred to the RPMI-1640 medium culture solution (containing $10 \%$ FBS, penicillin-streptomycin), and then cultured in an incubator $\left(37^{\circ} \mathrm{C}, 5 \% \mathrm{CO}_{2}\right)$ for 2-3 days. After that, passage was performed. Cells in logarithmic growth phase were prepared into $1 \times 10^{6}$ cells $/ \mathrm{ml}$ cell suspension using PBS buffer in order to establish an animal model.

Animal modeling and grouping. The cell suspension was inoculated into the subcutaneous side of the left back near the head of nude mice, reared by professionals for 3 weeks under SPF conditions. Subsequent experiments were performed after neoplasia. Sixty nude mice were randomized into the control group (blank particles), the low dose group $\left(1.48 \times 10^{-7} \mathrm{~Bq}\right.$ ${ }^{125} \mathrm{I}$ particles $)$, the medium dose group $\left(2.22 \times 10^{-7} \mathrm{~Bq}{ }^{125} \mathrm{I}\right.$ particles) and the high dose group $\left(2.96 \times 10^{-7} \mathrm{~Bq}^{125} \mathrm{I}\right.$ particles) $(\mathrm{n}=15$ per group). According to the principles of aseptic technique, a needle for particle implantation was implanted into the central region of the tumor based on the tumor diameter. After 4 weeks of implantation under SPF conditions, the nude mice in groups were separately reared in cages to avoid mutual biting.

Detection of tumor volume and mass. Six nude mice were randomly anesthetized with $10 \%$ chloral hydrate $(350 \mathrm{mg} / \mathrm{kg})$ by intraperitoneal injection and then sacrificed by cervical dislocation before implantation (day 0 ) and on the 7th, 14th, 21st and 28th day after implantation, respectively, in order to collect the tumor tissue and measure tumor volume and mass [Tumor volume $=$ long diameter $(\mathrm{mm}) \times$ short diameter $\left.\left(\mathrm{mm}^{2}\right) / 2\right]$.

Detection of apoptotic rate. After being anesthetized with $10 \%$ chloral hydrate $(350 \mathrm{mg} / \mathrm{kg}$ ) and then sacrificed by cervical dislocation, on the 28th day after implantation, the tumor tissue of nude mice was collected, fixed with 4\% paraformaldehyde, dehydrated with gradient ethanol, embedded with paraffin, and finally sectioned. The TUNEL (TdT-mediated dUTP nick-end labeling) apoptosis detection kit was used for detecting apoptosis of tumor cells, with the operation carried out in strict accordance with the kit instructions. After staining, the apoptotic cells in the visual field were observed and counted using an optical microscope (x400; Olympus). The apoptotic rate $=$ total number of apoptotic 
Table III. Comparison of tumor mass (g).

\begin{tabular}{|c|c|c|c|c|c|}
\hline Groups & $\begin{array}{c}\text { Before } \\
\text { implantation } \\
\text { (Day 0) }\end{array}$ & $\begin{array}{l}\text { 7th day } \\
\text { after } \\
\text { implantation }\end{array}$ & $\begin{array}{l}\text { 14th day } \\
\text { after } \\
\text { implantation }\end{array}$ & $\begin{array}{l}\text { 21st day } \\
\text { after } \\
\text { implantation }\end{array}$ & $\begin{array}{l}\text { 28th day } \\
\text { after } \\
\text { implantation }\end{array}$ \\
\hline Control group $(\mathrm{n}=6)$ & $2.032 \pm 0.044$ & $2.125 \pm 0.073$ & $2.131 \pm 0.051$ & $2.134 \pm 0.051$ & $2.137 \pm 0.066$ \\
\hline Low dose group $\left(\mathrm{n}=6,1.48 \times 10^{-7} \mathrm{~Bq}^{125} \mathrm{I}\right)$ & $2.030 \pm 0.061$ & $1.968 \pm 0.060^{\mathrm{e}}$ & $1.488 \pm 0.069^{\mathrm{a}, \mathrm{b}, \mathrm{e}}$ & $1.015 \pm 0.041^{\mathrm{a}-\mathrm{c}, \mathrm{e}}$ & $0.686 \pm 0.050^{\mathrm{a}-\mathrm{e}}$ \\
\hline Medium dose group $\left(\mathrm{n}=6,2.22 \times 10^{-7} \mathrm{~Bq}^{125} \mathrm{I}\right)$ & $2.035 \pm 0.049$ & $1.987 \pm 0.077^{\mathrm{e}}$ & $1.815 \pm 0.062^{a, b, e, f}$ & $1.435 \pm 0.052^{\mathrm{a}-\mathrm{c}, \mathrm{e}, \mathrm{f}}$ & $1.061 \pm 0.048^{\mathrm{a}-\mathrm{f}}$ \\
\hline High dose group $\left(\mathrm{n}=6,2.96 \times 10^{-7} \mathrm{~Bq}^{125} \mathrm{I}\right)$ & $2.044 \pm 0.052$ & $1.944 \pm 0.051^{\mathrm{a}, \mathrm{e}}$ & $1.752 \pm 0.070^{\mathrm{a}, \mathrm{b}, \mathrm{e}-\mathrm{g}}$ & $1.384 \pm 0.067^{\mathrm{a-c}, \mathrm{e}, \mathrm{f}}$ & $1.185 \pm 0.052^{\mathrm{a}-\mathrm{c}, \mathrm{e}-\mathrm{g}}$ \\
\hline
\end{tabular}

${ }^{\mathrm{a}} \mathrm{P}<0.05$ indicates a difference compared with before implantation, ${ }^{\mathrm{b}} \mathrm{P}<0.05$ indicates a difference compared with the 7 th day after implantation, ${ }^{\mathrm{c}} \mathrm{P}<0.05$ indicates a difference compared with the 14 th day after implantation. ${ }^{\mathrm{d}} \mathrm{P}<0.05$ indicates a difference compared with the 21 st day after implantation, ${ }^{\mathrm{e}} \mathrm{P}<0.05$ indicates a difference compared with the control group, ${ }^{\mathrm{f}} \mathrm{P}<0.05$ indicates a difference compared with the low dose group, ${ }^{\mathrm{g}} \mathrm{P}<0.05$ indicates that there is a difference compared with the medium dose group.

cells / total number of cells x $100 \%$. After nuclear staining, the nuclei of normal tumor cells were blue, but those of apoptotic tumor cells were yellow or brownish yellow. Five visual fields of each section were randomly observed.

Reverse transcription-quantitative polymerase chain reaction $(R T-q P C R)$ detection. After being anesthetized with $10 \%$ chloral hydrate $(350 \mathrm{mg} / \mathrm{kg})$ and then sacrificed by cervical dislocation, the tumor tissue of nude mice on the 28th day after implantation was collected. The TRIzol extraction reagent was used for extracting total RNA, ultraviolet spectrophotometer (BioRad) and agarose gel electrophoresis for detecting its purity, concentration and integrity. Of the total RNA, $1 \mu \mathrm{g}$ was reverse transcribed using $5 \mathrm{X}$ TransScript ${ }^{\circledR}$ II All-in-One SuperMix for PCR, with operations carried out in strict accordance with the manufacturer's kit. PCR amplification experiments were performed using the TransScript Two-Step SYBR-Green RT-PCR SuperMix kit, and the system was as follows: $1 \mu \mathrm{l}$ of cDNA, each $0.5 \mu \mathrm{l}$ of upstream and downstream primers, $12.5 \mu \mathrm{l}$ of $2 \mathrm{X}$ TransTaq ${ }^{\circledR}$ HiFi PCR SuperMix II, and finally Nechelase-free Water was added to total of $25 \mu \mathrm{l}$. Conditions were as follows: pre-denaturation at $94^{\circ} \mathrm{C}$ for $5 \mathrm{~min}$, denaturation at $94^{\circ} \mathrm{C}$ for $30 \mathrm{sec}$, annealing at $60^{\circ} \mathrm{C}$ for $30 \mathrm{sec}$, extension at $72^{\circ} \mathrm{C}$ for $30 \mathrm{sec}$, for 40 cycles. Three identical wells were set for each sample and the experiment was performed 3 times. GAPDH was used as an internal reference, and $2^{-\Delta \Delta c q}$ was used to analyze the data (13).

Statistical analysis. In this study, SPSS20.0 software package (Guangzhou Pomine Information Technology Co., Ltd.) was used for statistically analyzing the data, GraphPad Prism 7 (Cabit Information Technology Co., Ltd.) for plotting the figures. Measurement data were expressed as mean \pm standard deviation (mean $\pm \mathrm{SD}$ ), and comparison between two groups was tested by independent samples t-test and represented by t. Analysis of variance was used for comparison between groups, LSD-t test for pairwise comparison after that. $\mathrm{P}<0.05$ was considered to indicate a statistically significant difference.

\section{Results}

Modeling. Sixty nude mice were subjected to tumorigenicity experiments, and no mouse died during the modeling.
Comparison of tumor volume. In this study, there was no significant difference in the tumor volume between the groups before implantation $(\mathrm{P}>0.05)$. On the 7 th day after implantation, the tumor volume in the low, medium and high dose groups was significantly lower than that in the control group $(\mathrm{P}<0.05)$; there was no difference between the low and medium dose groups $(\mathrm{P}>0.05)$; the tumor volume in the low and medium dose groups was significantly lower than that in the high dose group $(\mathrm{P}<0.05)$. On the 14th day after implantation, the tumor volume in the low, medium and high dose groups was significantly lower than that in the control group $(\mathrm{P}<0.05)$, which in the medium dose group was significantly higher than that in the high dose group $(\mathrm{P}<0.05)$; there was no significant difference between the other groups $(\mathrm{P}>0.05)$. On the 21st day after implantation, the tumor volume in the low, medium and high dose groups was significantly lower than that in the control group $(\mathrm{P}<0.05)$; there was no difference between the other groups $(\mathrm{P}>0.05)$. On the 28th day after implantation, the tumor volume in the low, medium and high dose groups was significantly lower than that in the control group $(\mathrm{P}<0.05)$, which in the low dose group was significantly lower than that in the medium and high dose groups $(\mathrm{P}<0.05)$; there was no difference between the other groups $(\mathrm{P}>0.05)$. The comparison in the group showed that the tumor volume in the control group gradually increased with time, while that in the low, medium and high dose groups gradually decreased with time. In the control group, there was a significant difference between day 0 and on the 14th, 21st, 28th day $(\mathrm{P}<0.05)$; there was no significant difference between the other two time-points ( $\mathrm{P}>0.05)$. In the low dose group, there was no significant difference between the 14th day and the 21st day $(\mathrm{P}>0.05)$; there was a significant difference between the other time-points $(\mathrm{P}<0.05)$. In the medium dose group, there was a statistically significant difference between each time-point $(\mathrm{P}<0.05)$. In the high dose group, there was no difference between day 0 and the 7th day, as well as between the 14th day and 21st day $(\mathrm{P}>0.05)$; there was a significant difference between the other time-points $(\mathrm{P}<0.05)$ (Table II).

Comparison of tumor mass. There was no significant difference in the tumor mass between the groups before implantation $(\mathrm{P}>0.05)$. On the 7th day after implantation, the tumor mass in the low, medium and high dose groups was significantly lower 
Table IV. Apoptotic rates on the 28th day.

\begin{tabular}{lc}
\hline Groups & $\begin{array}{c}\text { Apoptotic } \\
\text { rate on the } \\
28 \text { th day }(\%)\end{array}$ \\
\hline Control group $(\mathrm{n}=6)$ & $7.24 \pm 1.78$ \\
Low dose group $\left(\mathrm{n}=6,1.48 \times 10^{-7} \mathrm{~Bq}^{125} \mathrm{I}\right)$ & $45.22 \pm 5.97^{\mathrm{a}}$ \\
Medium dose group $\left(\mathrm{n}=6,2.22 \times 10^{-7} \mathrm{~Bq}^{125} \mathrm{I}\right)$ & $35.12 \pm 4.22^{\mathrm{a}, \mathrm{b}}$ \\
High dose group $\left(\mathrm{n}=6,2.96 \times 10^{-7} \mathrm{~Bq}^{125} \mathrm{I}\right)$ & $40.54 \pm 4.35^{\mathrm{a}, \mathrm{b}}$ \\
F value & 92.188 \\
P-value & $<0.001$ \\
\hline
\end{tabular}

${ }^{\mathrm{a}} \mathrm{P}<0.05$ indicates a difference compared with the control group, ${ }^{\mathrm{b}} \mathrm{P}<0.05$ indicates a difference compared with the low dose group.

than that in the control group $(\mathrm{P}<0.05)$; there was no difference between the other groups $(\mathrm{P}>0.05)$. On the 14th day after implantation, the tumor mass in the low, medium and high dose groups was significantly lower than that in the control group, which in the medium and high dose groups was significantly higher than that in the low dose group, and which in the high dose group was significantly lower than that in the medium dose group $(\mathrm{P}<0.05)$. On the 21st day after implantation, there was no difference in the tumor mass between the medium and high dose groups $(\mathrm{P}>0.05)$; the tumor mass in the low, medium and high dose groups was significantly lower than that in the control group, which in the medium and high dose groups was significantly higher than that in the control group $(\mathrm{P}<0.05)$. On the 28th day after implantation, the tumor mass in the low, medium and high dose groups was significantly lower than that in the control group, which in the medium and high dose groups was significantly higher than that in the low dose group, and which in the high dose group was significantly higher than that in the medium dose group $(\mathrm{P}<0.05)$. The comparison in the group showed that the tumor mass in the control group gradually increased with time, while that in the low, medium and high dose groups gradually decreased with time. In the control group, there was no significant difference between each time-point $(\mathrm{P}>0.05)$. In the low dose group, there was no significant difference between day 0 and on the 7 th day $(\mathrm{P}>0.05)$; there was a significant difference between the other time-points $(\mathrm{P}<0.05)$. In the medium dose group, there was no significant difference between day 0 and the 7 th day $(\mathrm{P}>0.05)$; there was a significant difference between the other time-points $(\mathrm{P}<0.05)$. In the high dose group, there was no significant difference between the 21st and 28th day ( $P>0.05)$; there was a significant difference between the other time-points $(\mathrm{P}<0.05)$ (Table III).

Comparison of apoptosis. On the 28th day after implantation, there was a significant difference in the apoptotic rate between the groups $(\mathrm{P}<0.001)$. The apoptotic rate in the low, medium and high dose groups was significantly higher than that in the control group, which in the medium and high dose groups was significantly lower than that in the low dose group $(\mathrm{P}<0.001)$. There was no difference between other groups (P>0.05) (Table IV, Fig. 1).

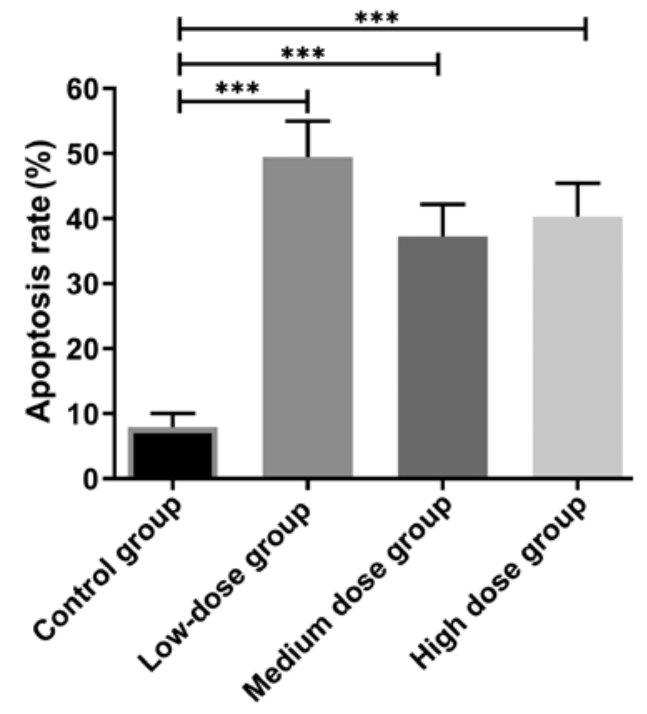

Figure 1. Tumor cell apoptosis on the 28th day. Apoptotic rate in the low, medium and high dose groups were higher than that in the control group. **** $\mathrm{P}<0.001$

Comparison of Bax, caspase-3 and caspase- 8 mRNA. On the 28 day after implantation, the relative expression of Bax, caspase-3 and caspase- 8 mRNA in the control group was significantly lower than that in the low, medium and high dose groups $(\mathrm{P}<0.05)$, which in the low dose group was significantly higher than that in the medium and high dose groups $(\mathrm{P}<0.05)$. There was no significant difference between the medium and high dose groups $(\mathrm{P}>0.05)$ (Table V, Fig. 2).

\section{Discussion}

Gastric cancer is a common malignant disease in the clinical department of gastroenterology and oncology. A cancer statistics report in the United States showed that there were 28,000 new patients and 15,700 deaths in 2017 (14). The disease is usually caused by changes in dietary habits, Helicobacter pylori infection, genetics and socioeconomic status among which the first one is the most common cause. Irregular diet, alcohol abuse, and lack of trace elements in daily diet lead to an increase in the incidence rate of the disease $(15,16)$. At present, gastric cancer is clinically treated by operation, but most patients after admission are in the middle and advanced stages of the disease and have missed the best treatment time, so they cannot be treated by operation (17). Radiotherapy, as an important means of the clinical treatment of cancer, has been widely used. According to a study, the survival time of patients with local advanced esophageal and gastric cancer after radiotherapy was significantly increased (18). However, traditional radiotherapy leads to necrosis in the normal tissue other than the lesion tissue during the treatment, and excessive radiation increases adverse reactions.

Internal radiotherapy has been gradually recognized by clinicians as medical technology continues to be improved, and its adjuvant treatment of malignant tumors has been widely used in clinical practice. ${ }^{125} \mathrm{I}$ is a synthetic isotope and has a long half-life (60.1d). Compared with traditional radiotherapy, it has a more appropriate radiation radius to accurately treat 
Table V. Comparison of Bax, caspase-3 and caspase- 8 mRNA on the 28th day.

\begin{tabular}{lccc}
\hline Groups & Bax & Caspase-3 & Caspase- 8 \\
\hline Control group $(\mathrm{n}=6)$ & $1.035 \pm 0.041$ & $1.024 \pm 0.032$ & $1.028 \pm 0.030$ \\
Low dose group $(\mathrm{n}=6)$ & $1.892 \pm 0.174^{\mathrm{a}}$ & $2.522 \pm 0.301^{\mathrm{a}}$ & $2.122 \pm 0.170^{\mathrm{a}}$ \\
Medium dose group $(\mathrm{n}=6)$ & $1.641 \pm 0.120^{\mathrm{a}, \mathrm{b}}$ & $1.891 \pm 0.260^{\mathrm{a}, \mathrm{b}}$ & $1.715 \pm 0.121^{\mathrm{a}, \mathrm{b}}$ \\
High dose group $(\mathrm{n}=6)$ & $1.705 \pm 0.081^{\mathrm{a}, \mathrm{b}}$ & $1.755 \pm 0.217^{\mathrm{a}, \mathrm{b}}$ & $1.658 \pm 0.148^{\mathrm{a}, \mathrm{b}}$ \\
F value & 62.461 & 43.962 & 73.853 \\
P-value & $<0.001$ & $<0.001$ & $<0.001$ \\
\hline
\end{tabular}

${ }^{\mathrm{a}} \mathrm{P}<0.05$, a difference compared with the control group, ${ }^{\mathrm{b}} \mathrm{P}<0.05$, a difference compared with the low dose group.

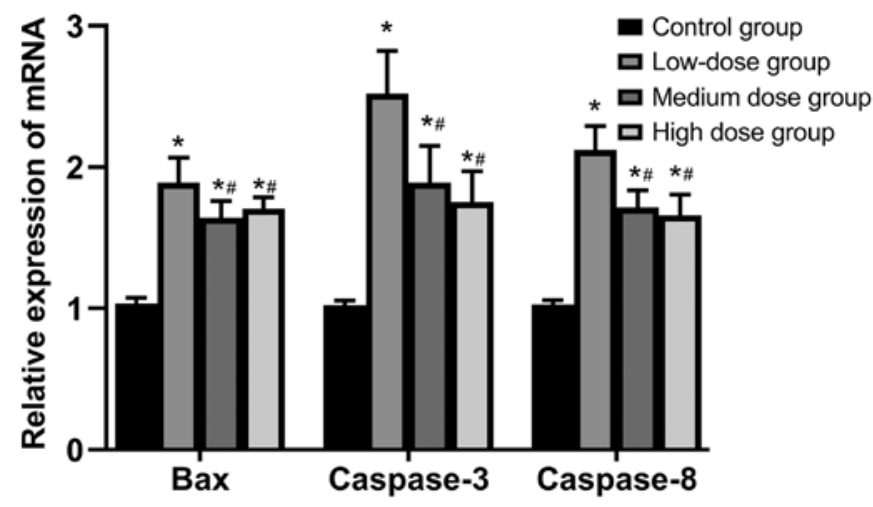

Figure 2. Expression levels of Bax, caspase-3 and caspase- 8 in tumor tissues. The relative expression of Bax, caspase- 3 and caspase- 8 mRNA in the control group was significantly lower than those in the low, medium and high dose groups. The expression levels of Bax, caspase- 3 and caspase- 8 mRNA in the low dose group were significantly higher than those in the medium and high dose groups $(\mathrm{P}<0.05)$. ${ }^{*} \mathrm{P}<0.05$, vs. the control group; ${ }^{*} \mathrm{P}<0.05$, vs. the low dose group.

the local area of lesions, and causes less trauma and damage to the normal tissue adjacent to lesions (19). In a study by Shi et al (20), the implantation of ${ }^{125} \mathrm{I}$ particles in patients with recurrent colorectal cancer significantly prolonged the survival time of the patients (21). In a study by Jiang et al (21), 56 lesions were treated through the implantation in patients with gastrointestinal cancer with pulmonary metastasis, with an overall local control rate of $91.1 \%$. These findings indicate that the transplantation of ${ }^{125} \mathrm{I}$ particles effectively inhibits tumor growth. Currently, clinical radiotherapy and chemotherapy affect tumor growth mainly through promoting tumor apoptosis (22). How do ${ }^{125} \mathrm{I}$ particles affect apoptotic factors in gastric cancer? Effects of radioactive ${ }^{125} \mathrm{I}$ on apoptosis at different doses in gastric cancer cells were investigated. In this study, a tumor-forming mouse model was established to observe the effects of radioactive ${ }^{125} \mathrm{I}$ particles at different doses on the tumor tissue, so as to provide a reference for clinical practice.

The proliferation of tumors is an important factor determining their growth rates. A tumor-forming mouse model was successfully established. The tumor volume and mass of nude mice in the low, medium and high groups gradually decreased with time, suggesting that ${ }^{125} \mathrm{I}$ particles can effectively inhibit the growth of gastric cancer tumors, probably because ${ }^{125} \mathrm{I}$ radiation directly destroys the DNA double strands of tumor cells and activates the expression of apoptotic factors in cells, thereby inducing apoptosis (23). Therefore, the apoptotic factors of gastric cancer tumors in nude mice were detected on the 28th day. Bax is a classical pro-apoptotic factor in the Bcl-2 family and lowly expressed in cells, and its expression is significantly increased when cells undergo apoptosis (24). Caspase-3 and caspase- 8 belong to the Caspase family; Caspase- 8 plays an important role in the activation of apoptosis and caspase-3 playing an important role during apoptosis (25). A study shows that the activation of them promotes apoptosis (26). In this study, on the 28th day after implantation, the relative expression of Bax, caspase- 3 and caspase- 8 mRNA in the low, medium and high groups was significantly higher than that in the control group, which indicates that ${ }^{125} \mathrm{I}$ particles can promote expression of Bax, caspase- 3 and caspase- 8 mRNA in gastric cancer tumors and thereby promote apoptosis. According to TUNEL, apoptosis in the low, medium and high groups was significantly higher than that in the control group. Sun et al (27) treated patients with stage IIIB-IV lung cancer by EGFR-TKI combined with the implantation of ${ }^{125} \mathrm{I}$ particles, and the expression of Bax in the tissue of the patients was significantly increased 1 month later. In a study by Wang et al (28), compared with high-dose $60 \mathrm{Co}$, the expression of Bax and caspase- 3 was significantly increased after low-dose ${ }^{125} \mathrm{I}$ radiation to lung cancer cells A549 and H1299.

In a study by Chen and Wang (29), the expression of caspase- 8 was significantly increased through ${ }^{125} \mathrm{I}$ irradiation to a rat model of glioma. In HGC-27 gastric cancer cell transplants in nude mice, ${ }^{125} \mathrm{I}$ particles effectively increased the expression of Bax, caspase- 3 and caspase- 8 mRNA in gastric cancer tumors, indicating that ${ }^{125} \mathrm{I}$ particles can increase the expression of Bax, caspase- 3 and caspase- 8 mRNA in tumor cells and promote apoptosis. However, on the 28th day after implantation, the tumor volume and mass in the low dose group were significantly lower than those in the medium and high dose groups, while the expression of Bax, caspase-3, caspase- 8 mRNA and apoptosis were significantly higher than those in the medium and high dose groups. These findings suggest that low-dose ${ }^{125} \mathrm{I}$ particles are significantly more effective than medium- and high-dose ${ }^{125} \mathrm{I}$ particles in inhibiting the growth of gastric cancer tumors. In a study by Lehmann and Dröge (30), the apoptotic rate of HeLa cells after 5 Gy ${ }^{125} \mathrm{I}$ irradiation was significantly higher than that after $10 \mathrm{~Gy}{ }^{125} \mathrm{I}$ irradiation. The above is similar to the results 
of our study, possibly because tumor cells increase their own adaptability and protection during the growth in order to avoid the toxic effects of radiation, resulting in resistance which is often referred to as the inverse dosage effect (31).

The present study showed that low-dose ${ }^{125}$ I was significantly more effective than medium- and high-dose ${ }^{125} \mathrm{I}$ in inhibiting the growth of HGC-27 gastric cancer cell transplants. However, there are still deficiencies. This animal experiment was not clinically verified, and the expression of Bax, caspase- 3 and caspase- 8 mRNA at other time-points was not detected. Thus further confirmational studies are required.

In summary, ${ }^{125}$ I particles can inhibit the growth of HGC-27 gastric cancer cell transplants, and promote the expression of Bax, caspase- 3 and caspase- 8 mRNA in the tumor tissue. Low-dose ${ }^{125} \mathrm{I}$ particles are significantly more effective than medium- and high-dose ${ }^{125} \mathrm{I}$ particles.

\section{Acknowledgements}

Not applicable.

\section{Funding}

No funding was received.

\section{Availability of data and materials}

The datasets used and/or analyzed during the present study are available from the corresponding author on reasonable request.

\section{Authors' contributions}

YY wrote the manuscript. YY and AC were responsible for animal modeling. JM and AW performed PCR and TUNEL assay. FX contributed to detection of tumor volume and mass. All the authors read and approved the final manuscript.

\section{Ethics approval and consent to participate}

The study was approved by the Ethics Committee of Huai'an TCM Hospital Affiliated to Nanjing University of Chinese Medicine (Huai'an, China).

\section{Patient consent for publication}

Not applicable.

\section{Competing interests}

The authors declare that they have no competing interests.

\section{References}

1. Torre LA, Bray F, Siegel RL, Ferlay J, Lortet-Tieulent J and Jemal A: Global cancer statistics, 2012. CA Cancer J Clin 65: 87-108, 2015.

2. Rahib L, Smith BD, Aizenberg R, Rosenzweig AB, Fleshman JM and Matrisian LM: Projecting cancer incidence and deaths to 2030: The unexpected burden of thyroid, liver, and pancreas cancers in the United States. Cancer Res 74: 2913-2921, 2014.
3. Chen W, Zheng R, Baade PD, Zhang S, Zeng H, Bray F, Jemal A, Yu XQ and He J: Cancer statistics in China, 2015. CA Cancer J Clin 66: 115-132, 2016.

4. Kim W, Kim HH, Han SU, Kim MC, Hyung WJ, Ryu SW, Cho GS, Kim CY, Yang HK, Park DJ, et al; Korean Laparoendoscopic Gastrointestinal Surgery Study (KLASS) Group: Decreased morbidity of laparoscopic distal gastrectomy compared with open distal gastrectomy for stage I gastric cancer: Short-term outcomes from a multicenter randomized controlled trial (KLASS-01). Ann Surg 263: 28-35, 2016.

5. Li P, Chen S, Chen H, Mo X, Li T, Shao Y, Xiao B and Guo J: Using circular RNA as a novel type of biomarker in the screening of gastric cancer. Clin Chim Acta 444: 132-136, 2015.

6. Obi N, Eulenburg C, Seibold P, Eilber U, Thöne K, Behrens S, Chang-Claude J and Flesch-Janys D: Associations between adjuvant radiotherapy and different causes of death in a German breast cancer cohort. Breast 38: 75-80, 2018.

7. Manocha R, Marks GB, Kenchington P, Peters D and Salome CM: Sahaja yoga in the management of moderate to severe asthma: A randomised controlled trial. Thorax 57: 110-115, 2002.

8. Vilgrain V, Pereira H, Assenat E, Guiu B, Ilonca AD, Pageaux GP, Sibert A, Bouattour M, Lebtahi R, Allaham W, et al; SARAH Trial Group: Efficacy and safety of selective internal radiotherapy with yttrium-90 resin microspheres compared with sorafenib in locally advanced and inoperable hepatocellular carcinoma (SARAH): An open-label randomised controlled phase 3 trial. Lancet Oncol 18: 1624-1636, 2017.

9. Huo X, Wang H, Yang J, Li X, Yan W, Huo B, Zheng G, Chai S, Wang J, Guan Z, et al: Effectiveness and safety of CT-guided (125)I seed brachytherapy for postoperative locoregional recurrence in patients with non-small cell lung cancer. Brachytherapy 15: 370-380, 2016.

10. Kittel JA, Reddy CA, Smith KL, Stephans KL, Tendulkar RD, Ulchaker J, Angermeier K, Campbell S, Stephenson A, Klein EA, et al: Long-term efficacy and toxicity of low-dose-rate ${ }^{125} \mathrm{I}$ prostate brachytherapy as monotherapy in low-, intermediate-, and high-risk prostate cancer. Int J Radiat Oncol Biol Phys 92: 884-893, 2015.

11. Wang GC, Liu F, Xie TH, Liu FL and Zhang CQ: Combined intestinal and biliary stenting in gastric outlet and biliary obstruction. Gastroenterology Res 2: 29-34, 2009.

12. Chen K, Li G, Geng F, Zhang Z, Li J, Yang M, Dong L and Gao F: Berberine reduces ischemia/reperfusion-induced myocardial apoptosis via activating AMPK and PI3K-Akt signaling in diabetic rats. Apoptosis 19: 946-957, 2014.

13. Livak KJ and Schmittgen TD: Analysis of relative gene expression data using real-time quantitative PCR and the 2(-Delta Delta $\mathrm{C}(\mathrm{T})$ ) method. Methods 25: 402-408, 2001.

14. Siegel RL, Miller KD and Jemal A: Cancer statistics, 2017. CA Cancer J Clin 67: 7-30, 2017.

15. Karimi P, Islami F, Anandasabapathy S, Freedman ND and Kamangar F: Gastric cancer: Descriptive epidemiology, risk factors, screening, and prevention. Cancer Epidemiol Biomarkers Prev 23: 700-713, 2014.

16. Plummer M, Franceschi S, Vignat J, Forman D and de Martel C: Global burden of gastric cancer attributable to Helicobacter pylori. Int J Cancer 136: 487-490, 2015.

17. Neugut AI, Hayek M and Howe G: Epidemiology of gastric cancer. Semin Oncol 23: 281-291, 1996.

18. Katai H, Mizusawa J, Katayama H, Takagi M, Yoshikawa T, Fukagawa T, Terashima M, Misawa K, Teshima S, Koeda K, et al: Short-term surgical outcomes from a phase III study of laparoscopy-assisted versus open distal gastrectomy with nodal dissection for clinical stage IA/IB gastric cancer: Japan Clinical Oncology Group Study JCOG0912. Gastric Cancer 20: 699-708, 2017.

19. $\mathrm{Ng} \mathrm{J}$ and Lee P: The role of radiotherapy in localized esophageal and gastric cancer. Hematol Oncol Clin North Am 31: 453-468, 2017.

20. Shi L, Li X, Pei H, Zhao J, Qiang W, Wang J, Xu B, Chen L, Wu J, Ji M, et al: Phase II study of computed tomography-guided (125)I-seed implantation plus chemotherapy for locally recurrent rectal cancer. Radiother Oncol 118: 375-381, 2016.

21. Jiang Y, Huang ZL, Wu PH, Zhang FJ, Zhao M, Huang JH, Fan WJ, Li CX, Gu YK, Zhang L, et al: Short-term efficacy of ct-guided radioactive seed ${ }^{125} \mathrm{I}$ implantation on residual or relapsing metastatic lymph nodes in advanced tumor patients after multi-modality treatment. Ai Zheng 27: 1082-1087, 2008 (In Chinese). 
22. Xie L, Chen Y, Zhang Y, Yang Z, Zhang Z, Shen L, Yuan Z and Ren M: Status and prospects of percutaneous vertebroplasty combined with ${ }^{125}$ I seed implantation for the treatment of spinal metastases. World J Surg Oncol 13: 119, 2015.

23. Safarzadeh E, Sandoghchian Shotorbani S and Baradaran B: Herbal medicine as inducers of apoptosis in cancer treatment Adv Pharm Bull 4 (Suppl 1): 421-427, 2014.

24. Chen W, Kang J, Xia J, Li Y, Yang B, Chen B, Sun W, Song X, Xiang W, Wang X, et al: p53-related apoptosis resistance and tumor suppression activity in UVB-induced premature senescent human skin fibroblasts. Int J Mol Med 21: 645-653, 2008

25. Pu X, Storr SJ, Zhang Y, Rakha EA, Green AR, Ellis IO and Martin SG: Caspase-3 and caspase-8 expression in breast cancer: Caspase-3 is associated with survival. Apoptosis 22: 357-368, 2017.

26. Dubey M, Nagarkoti S, Awasthi D, Singh AK, Chandra T, Kumaravelu J, Barthwal MK and Dikshit M: Nitric oxidemediated apoptosis of neutrophils through caspase- 8 and caspase-3-dependent mechanism. Cell Death Dis 7: e2348, 2016.

27. Sun W, Yuan X, Tian Y, Wu H, Xu H, Hu G and Wu K: Non-invasive approaches to monitor EGFR-TKI treatment in non-small-cell lung cancer. J Hematol Oncol 8: 95, 2015.
28. Wang Z, Zhao Z, Lu J, Chen Z, Mao A, Teng G and Liu F: A comparison of the biological effects of ${ }^{125}$ I seeds continuous lowdose-rate radiation and 60Co high-dose-rate gamma radiation on non-small cell lung cancer cells. PLoS One 10: e0133728, 2015.

29. Chen F and Wang D: Inhibition of glioblastoma growth and invasion by ${ }^{125} \mathrm{I}$ brachytherapy in rat glioma model. Am J Transl Res 9: 2243-2254, 2017.

30. Lehmann V and Dröge W: Demonstration of membrane receptors for human natural and recombinant ${ }^{125}$ I-labeled tumor necrosis factor on HeLa cell clones and their role in tumor cell sensitivity. Eur J Biochem 158: 1-5, 1986.

31. Ling CC, Gerweck LE, Zaider M and Yorke E: Dose-rate effects in external beam radiotherapy redux. Radiother Oncol 95: 261-268, 2010.

(i) () $($ This work is licensed under a Creative Commons EY Ac No Attribution-NonCommercial-NoDerivatives 4.0 International (CC BY-NC-ND 4.0) License. 